This document was prepared in conjunction with work accomplished under Contract No. DE-AC09-96SR18500 with the U.S. Department of Energy.

This work was prepared under an agreement with and funded by the U.S. Government. Neither the U. S. Government or its employees, nor any of its contractors, subcontractors or their employees, makes any express or implied: 1 . warranty or assumes any legal liability for the accuracy, completeness, or for the use or results of such use of any information, product, or process disclosed; or 2 . representation that such use or results of such use would not infringe privately owned rights; or 3 . endorsement or recommendation of any specifically identified commercial product, process, or service. Any views and opinions of authors expressed in this work do not necessarily state or reflect those of the United States Government, or its contractors, or subcontractors. 
PVP2008-61591

\section{Evaluation of Thermal Conductivity of Installed-in-Place Polyurethane Foam Insulation by Experiment and Analysis.}

\author{
Allen C. Smith \\ Savannah River National Laboratory \\ Washington Savannah River Company \\ Aiken, South Carolina 29808 \\ (803) 725 2943, allen.smith@srnl.doe.gov \\ Bruce J. Hardy \\ Savannah River National Laboratory \\ Washington Savannah River Company \\ Aiken, South Carolina 29808 \\ (803) 725 7310, bruce.hardy@srnl.doe.gov
}

\author{
Narendra K. Gupta \\ Savannah River National Laboratory \\ Washington Savannah River Company \\ Aiken, South Carolina 29808 \\ (803) 725 5300, nick.gupta@srnl.doe.gov \\ Kurt R. Eberl \\ Savannah River National Laboratory \\ Washington Savannah River Company \\ Aiken, South Carolina 29808 \\ (803) 725 2656, kurt.eberl@srnl.doe.gov
}

\begin{abstract}
In the thermal analysis of the 9977 package, it was found that calculated temperatures, determined using a typical thermal analysis code, did not match those measured in the experimental apparatus. The analysis indicated that the thermal resistance of the overpack in the experimental apparatus was less than that expected, based on manufacturer's reported value of thermal conductivity. To resolve this question, the thermal conductivity of the installed foam was evaluated from the experimental results, using a simplified analysis. This study confirmed that the thermal resistance of the experimental apparatus was lower than that which would result from the manufacturer's published values for thermal conductivity of the foam insulation. The test package was sectioned to obtain samples for measurement of material properties. In the course of the destructive examination a large uninsulated region was found at the bottom of the package, which accounted for the anomalous results. Subsequent measurement of thermal conductivity confirmed the manufacturer's published values. The study provides useful insight into the use of simplified, scoping calculations for evaluation of thermal performance of packages.
\end{abstract}

\section{INTRODUCTION}

The 9977 is a drum type package capable of transporting a wide range of contents, including those of the $6 \mathrm{M}$ specification package. It employs a Chalfant type containment vessel, protected by a stainless steel drum overpack. Polyurethane foam provides impact protection and thermal insulation for the containment vessel. An inner layer of Fiberfrax insulation provides additional thermal protection for the containment vessel.

In the NCT thermal analysis of the 9977, it was found that calculated temperatures did not match those measured in the experimental apparatus used to confirm the NCT performance of the package. The results indicated that the thermal resistance of the overpack in the experimental apparatus was less than that expected, based on thermal properties of the foam and Fiberfrax determined from manufacturer's information. Subsequently, by using an adjusted thermal conductivity for the foam, a calculated temperature distribution was obtained which was in good agreement with the experimental results (Reference 1). This left unresolved the question of why the computational results and experimental results were inconsistent.

To resolve this question, the value of thermal conductivity of the foam in the experimental package was determined from the measured temperatures by a simplified analysis using the classical heat conduction equations. This evaluation estimates the thermal conductivity for the foam from the temperatures measured at the inside and outside limits of the foam and the heat flux imposed on the test package. 
Two approaches were followed, a very simplified 1-D approximation and a more comprehensive quasi 2-D approximation. For the 1-D evaluation the package was treated as a hollow cylinder, with all the heat being transferred radially. For the quasi 2-D evaluation, the distribution of heat flow over the surface is estimated and $\mathrm{k}$ determined for a region in which the heat transfer is axially uniform.

\section{Test and Analytical Results}

The thermal conductivity of the test and adjusted value needed for the analytical temperature results to agree are:

Manufacturer's data: $\mathrm{k}=0.027$ to $0.031 \mathrm{Btu} / \mathrm{hr} \mathrm{ft} \mathrm{F}$

Adjusted value for analysis: $\mathrm{k}=0.0525$

The instrumentation arrangement for the Environmental Chamber NCT test of the 9977 is shown in Figure 1. The test package, SN-6, contained a surrogate contents with 19 watt internal heater. The environmental test chamber provide a controlled peak ambient temperature of $38 \mathrm{C}(100 \mathrm{~F})$ as required by 10CFR71.71(b). The package component temperatures in the elevation of the surrogate contents are given in Table 1.

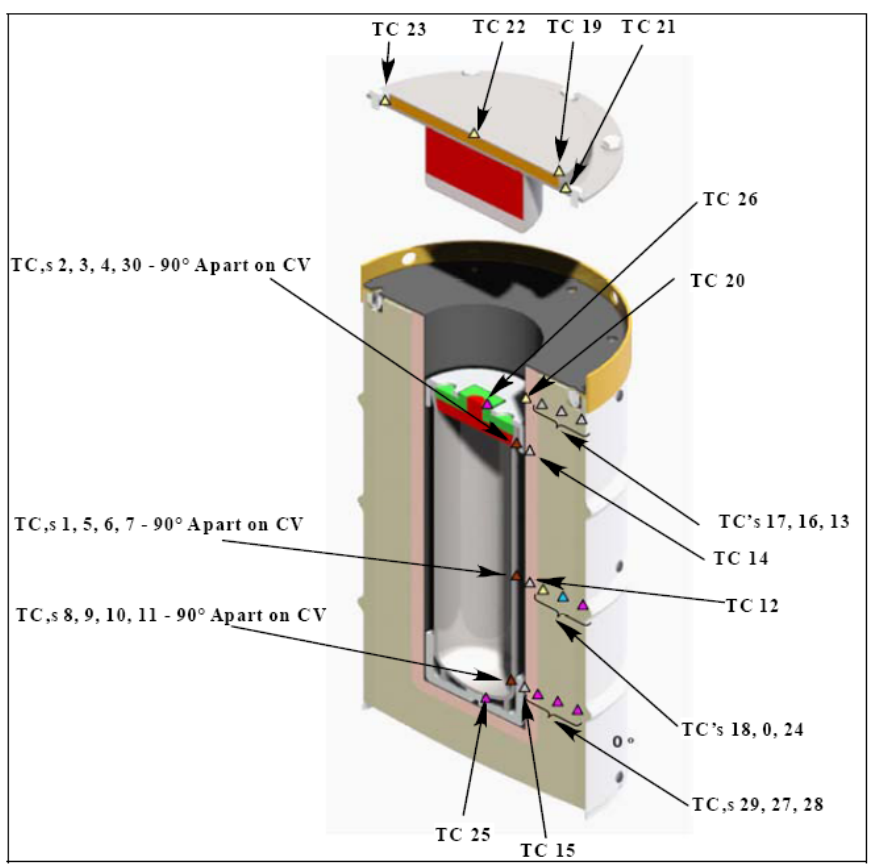

Figure 1. Location of Thermocouples in Experimental Package SN-6.
Table 1. Experimental Results for SN-6

\begin{tabular}{|l|l|l|}
\hline \multicolumn{3}{|c|}{$\begin{array}{c}\text { Temperatures for } 19 \mathrm{w} \text { internal heat generation and 38C } \\
\text { environmental condition. }\end{array}$} \\
\hline Thermocouple & Location & Temperature, F \\
\hline TC-12 & & 120 \\
\hline TC-13 & & 108 \\
\hline TC-18 & & 157 \\
\hline TC-24 & & 107 \\
\hline TC-28 & & 107 \\
\hline TC-29 & & 164 \\
\hline
\end{tabular}

\section{One Dimensional Estimate}

The following assumptions were used for the simplified, one-dimensional estimate:

All heat transfer is radial.

Interior temperature is the average of experimentally measured inner temperatures for foam.

Exterior temperature is the average of experimentally measured outer temperatures for the foam.

Heat transfer is $19 \mathrm{w}$ or $65 \mathrm{Btu} / \mathrm{hr}$.

Compressed Fiberfrax thickness is 0.5 in.

ID of foam = ID of liner +2 (liner thickness $)+$ 2(compressed Fiberfrax thickness) $=9.35$

Using temperatures reported in Reference 2:

Tavg inner $=(\mathrm{T} 29+\mathrm{T} 18+\mathrm{T} 12) / 3=147 \mathrm{~F}$

Tavg outer $=(\mathrm{T} 28+\mathrm{T} 24+\mathrm{T} 13) / 3=107.3 \mathrm{~F}$

For a hollow cylinder:

$\mathrm{q}=2 \pi \mathrm{kL}(\mathrm{Ti}-\mathrm{To}) / \ln \left(\mathrm{r}_{\mathrm{o}} / \mathrm{r}_{\mathrm{i}}\right)$

Where:

$\mathrm{L}$ is the length of the section

$\mathrm{q}$ is the rate of heat transfer through the section

$r_{i}$ is the inner radius $=4.675$ in.

$r_{0}$ is the outer radius $=9$ in.

$\mathrm{Ti}$ is the inside temperature

To is the outside temperature

$\mathrm{k}$ is the thermal conductivity

Solving for thermal conductivity:

$$
\begin{aligned}
\mathrm{k}= & (\mathrm{q} / 2 \pi \mathrm{L})\left(\left(\ln \left(\mathrm{r}_{\mathrm{o}} / \mathrm{r}_{\mathrm{i}}\right) /(\mathrm{Ti}-\mathrm{To})\right)\right. \\
= & ((65 \mathrm{Btu} / \mathrm{hr}) /((2 \pi) \quad(3 \mathrm{ft})))((\ln (9 / 4.675)) /(147 \mathrm{~F}- \\
& 107 \mathrm{~F}))=0.0565 \mathrm{Btu} / \mathrm{hr} \mathrm{ft} \mathrm{F}
\end{aligned}
$$




\section{Refined Estimate}

To obtain an improved estimate, the variation of heat flux over the package was evaluated. The process was as follows:

The heat flux distribution was approximated, based on obtained from the analytical results for the reference case (the General NCT Model) as shown in Figure 2 (Reference 1). To accomplish this, the liner inner surface, including the bottom of the top plug, was divided into segments. The heat transfer in each segment was determined, based on an assumed thermal conductivity and the temperatures calculated by the analysis for the inside and outside of the segment. The total heat transfer was determined and compared to the heat generated in the package. The distribution of heat flux was assumed to be essentially the same as for the test package. Using the fraction of the heat transferred through a know region and the measured temperatures across the region, the thermal conductivity could be determined.

In this analysis, the liner was divided into 16 sections, two circumferential, at the top and at the bottom, and 12 axial locations. A spread sheet was developed to calculate the total heat transfer, for the calculated temperature distribution and an assumed foam thermal conductivity.

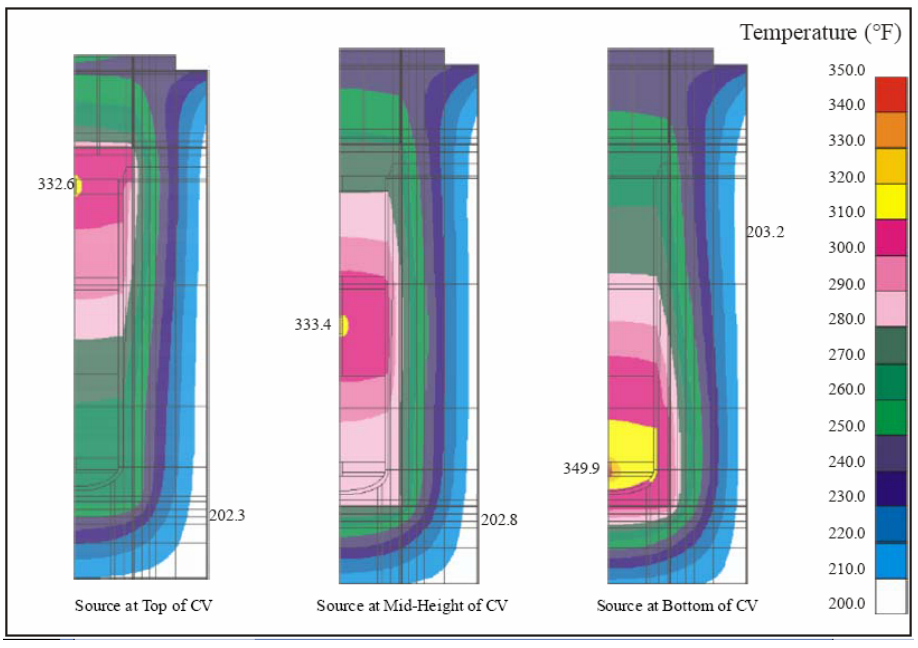

Figure 2. Calculated temperature distributions for various heat source locations. The simplified analysis assumed the heat source was at the bottom of the package (Figure 15 from Reference 1).

For the axial heat conduction through the top and bottom:

$\mathrm{q}=-\mathrm{kA} \mathrm{A}_{\mathrm{n}}\left(\Delta \mathrm{t}_{\mathrm{n}} / \Delta \mathrm{z}_{\mathrm{n}}\right)$

where $\mathrm{n}$ is 1 or 2 for the top and 15 or 16 , for the bottom.
At the top and bottom, the segments were a central circular segment with radius of $2.625 \mathrm{in}$. and an outer annular segment with outer radius of $4.675 \mathrm{in}$. The corresponding areas for heat transfer are: $\mathrm{A}_{1}=\pi\left(\mathrm{r}_{1}\right)^{2}=0.1503 \mathrm{ft}^{2}$, and $\mathrm{A}_{2}=\pi\left(\mathrm{r}_{1}{ }^{2}-\mathrm{r}_{2}{ }^{2}\right)=$ $0.3265 \mathrm{ft}^{2}$.

The thermal conductivity of the top plug insulating material is $0.0633 \mathrm{Btu} / \mathrm{hr} \mathrm{ft} \mathrm{F}$. The bottom insulation was intended to be foam.

The heat transfer through the sides of the package is radial. For the radial conduction sections representing the liner region:

$$
\mathrm{q}_{\mathrm{n}}=(2 \pi \mathrm{k} \Delta \mathrm{L})\left(\mathrm{Ti}_{\mathrm{n}}-\mathrm{To}_{\mathrm{n}}\right) /\left(\ln \left(\mathrm{r}_{\mathrm{o}} / \mathrm{r}_{\mathrm{i}}\right)\right)
$$

The height of the liner cavity, Hc, is 24.89 in.

There are 12 sections in the liner region, so the height of each section is: $\Delta \mathrm{L}=2.07 \mathrm{in}$.

The inner and outer radii of the foam, $r_{i}$ and $r_{0}$, are 4.675 in. and 9 in., respectively.

The bottom foam thickness, $\Delta \mathrm{z}$, is $3.68 \mathrm{in}$.

In order to calculate the heat transfer through each section, the section thermal conductivity and inner and outer temperatures are needed. The temperatures were obtained from the temperature distribution for the reference case (Figure 2). Various values of thermal conductivity were assumed and the heat transfer for each section was calculated. The total heat transfer was obtained by summing the heat transfer for each segment. This calculated total heat transfer was compared to the heat generated, $19 \mathrm{w}(65 \mathrm{Btu} / \mathrm{hr})$ and the value of thermal conductivity was adjusted until the calculated heat transfer was equal to the heat generation. Because of the simplified calculation scheme is not truly Two-Dimensional, the resulting value of thermal conductivity would not be expected to be the same as the published data. The thermal conductivity required was found to correspond to a foam thermal conductivity of: $\mathrm{k}$ $=0.038 \mathrm{Btu} / \mathrm{hr} \mathrm{ft} \mathrm{F}$.

The results showed that the heat transfer in the lower end of the liner was essentially one dimensional and constant over four sections which surrounded the lower thermocouple location of the experimental unit. 


\begin{tabular}{|c|c|c|c|c|c|c|}
\hline \multicolumn{7}{|c|}{ Estimate of heat flux distribution for 9977} \\
\hline \multicolumn{4}{|c|}{ Total heat transfer $=19 \mathrm{w}$ or $65 \mathrm{Btu} / \mathrm{hr}$} & & & \\
\hline $\mathrm{ri}=$ & 4.675 & $\mathrm{dL}=$ & 2.07 & \multicolumn{2}{|c|}{ Dimensions in in. } & \\
\hline ro $=$ & & dY1 = & 6 & & & \\
\hline $\mathrm{r} 1=$ & 2.625 & dY16 = & 3.68 & $\ln (\mathrm{ro} / \mathrm{ri})=$ & 0.654995 & \\
\hline $\mathrm{r} 2=$ & 4.675 & & & & & \\
\hline $\mathrm{k} 1=$ & 0.0633 & $\mathrm{~B} / \mathrm{hr} \mathrm{ft} F$ & $\mathrm{~A} 1=$ & 0.15035 & $\mathrm{ft}^{\wedge} 2$ & \\
\hline $\mathrm{k}$ foam $=$ & 0.038 & & $\mathrm{~A} 2=$ & 0.3265 & & \\
\hline HT path & A axial & $\mathrm{dL}, \mathrm{ft}$ & $\mathrm{Ti}, \mathrm{F}$ & To & $\mathrm{k}$ & $\mathrm{q}, \mathrm{B} / \mathrm{hr}$ \\
\hline 1 & 0.15035 & 0.5 & 260 & 240 & 0.0633 & 0.031724 \\
\hline 2 & 0.3265 & 0.5 & 260 & 240 & 0.0633 & 0.068892 \\
\hline 3 & & 0.1725 & 260 & 203 & 0.038 & 3.584172 \\
\hline 4 & & 0.1725 & 263 & 203 & 0.038 & 3.772812 \\
\hline 5 & & 0.1725 & 267 & 203 & 0.038 & 4.024333 \\
\hline 6 & & 0.1725 & 270 & 203 & 0.038 & 4.212974 \\
\hline 7 & & 0.1725 & 275 & 203 & 0.038 & 4.527375 \\
\hline 8 & & 0.1725 & 280 & 203 & 0.038 & 4.841776 \\
\hline 9 & & 0.1725 & 285 & 203 & 0.038 & 5.156177 \\
\hline 10 & & 0.1725 & 290 & 203 & 0.038 & 5.470578 \\
\hline 11 & & 0.1725 & 297 & 203 & 0.038 & 5.910739 \\
\hline 12 & & 0.1725 & 300 & 203 & 0.038 & 6.09938 \\
\hline 13 & & 0.1725 & 300 & 203 & 0.038 & 6.09938 \\
\hline 14 & & 0.1725 & 300 & 203 & 0.038 & 6.09938 \\
\hline 15 & 0.3265 & 0.306667 & 300 & 210 & 0.038 & 3.641185 \\
\hline 16 & 0.15035 & 0.306667 & 300 & 215 & 0.038 & 1.583578 \\
\hline & & & & & Qtotal = & 65.12445 \\
\hline & & & & & & \\
\hline & & & & & Qactual = & $5 \mathrm{~b} / \mathrm{hr}$ \\
\hline
\end{tabular}

Figure 3. Spread sheet for determining heat flux distribution.

The reference case had a higher surface temperature than the experimental case. It is assumed that the heat flux distribution is approximately the same for both cases. The heat transfer through these four sections was $24 \mathrm{~b} / \mathrm{hr} \mathrm{ft} \mathrm{F}$, of the total of $65 \mathrm{~B} / \mathrm{hr} \mathrm{ft} \mathrm{F}$.

Solving the expression for radial heat transfer in a hollow cylinder for thermal conductivity and substituting for the temperatures measured in the experiment, we have:

$$
\mathrm{k}=\mathrm{q}\left(\ln \left(\mathrm{r}_{\mathrm{o}} / \mathrm{r}_{\mathrm{i}}\right)\right) /\left(2 \pi \Delta \mathrm{L}\left(\mathrm{Ti}_{\mathrm{n}}-\mathrm{To}_{\mathrm{n}}\right)\right)
$$

The region where the heat transfer is most uniform corresponds to the location of thermocouples 27 and 29 of the experimental apparatus.

For this group of sections:

$$
\begin{aligned}
& \mathrm{q}=24 \mathrm{btu} / \mathrm{hr} \\
& \mathrm{Ti}=164 \mathrm{~F} \\
& \mathrm{To}=107 \mathrm{~F} \\
& \Delta \mathrm{L}=8.3 \mathrm{in} .=0.69 \mathrm{ft} \\
& \ln \left(\mathrm{r}_{\mathrm{o}} / \mathrm{r}_{\mathrm{i}}\right)=0.655
\end{aligned}
$$

Substituting,

$$
\begin{aligned}
\mathrm{k} & =(1 /(2 \pi(0.69) \mathrm{ft}))((24 \mathrm{Btu} / \mathrm{hr})(0.655) /(164-107) \mathrm{F} \\
& =0.0636 \mathrm{Btu} / \mathrm{hr} \mathrm{ft} \mathrm{F}
\end{aligned}
$$

\section{Measured Thermal Conductivity}

In order to understand this inconsistency, direct measurement of the thermal conductivity of the installed foam was necessary. Accordingly, the test package was sectioned to obtain samples for structural and thermal testing. This destructive disassembly of the test package revealed a significant void (an un-insulated region) at the bottom of the package which was not accounted for in the computational model. Correction of the computational model for the presence of this void, and using the manufacturer's published value for thermal conductivity, resulted in agreement between the experiment and analytical results.

The thermal conductivity of the installed foam, in the radial direction was determined for three specimens. These

\begin{tabular}{|c|c|c|c|c|c|}
\hline $\begin{array}{l}\text { Specimen } \\
\text { ID }\end{array}$ & $\begin{array}{c}\text { Test } \\
\text { Location }\end{array}$ & $\begin{array}{l}\text { Mean } \\
\text { Temp. } \\
\text { (F) }\end{array}$ & $\begin{array}{c}\text { Thermal } \\
\text { Conductivity } \\
\text { (Btu/hr-ft- } \\
\left.{ }^{\circ} \mathrm{F}\right)\end{array}$ & $\begin{array}{l}\text { Nominal } \\
\text { Thermal } \\
\text { Cond. at } \\
\text { Specimen } \\
\text { Density* } \\
\text { (Btu/hr- } \\
\left.\text { ft- }{ }^{\circ} \mathrm{F}\right)\end{array}$ & $\begin{array}{l}\text { Density } \\
\left(\mathrm{lb} / \mathrm{ft}^{3}\right)\end{array}$ \\
\hline 1 & Sidewall & 75.48 & 0.02844 & 0.0301 & 18.49 \\
\hline 2 & Sidewall & 75.39 & 0.02824 & 0.0297 & 18.07 \\
\hline 3 & Sidewall & 75.46 & 0.02809 & 0.0306 & 19.13 \\
\hline
\end{tabular}
were taken from adjacent slices from the side of the package. The cuts were parallel and the plane of the cuts was parallel to the axis of the package, so that the cuts were chords of the package cross section (Reference 3 ). The results are given in Table 2 .

Table 2. Summary and Comparison of SN-6 in-situ Thermal Conductivity Results

\section{Discussion}

As noted, the discrepancy between the analytical results and the experimental results was the result of the presence of an un-insulated void in the bottom of the package. When the computational model was corrected to represent the void, good agreement with the experimental results was obtained.

The simplified approximation represented the same configuration as the original analytical model (i.e., before the void was discovered and incorporated into the model). So, the simplified model could be compared with the analytical model results. The simplified results yielded a thermal conductivity within about $20 \%$ of the adjusted value used in the analysis. That is, the value required for the analytical model to match the 
experimental temperatures. The 1-D model provided even closer results, in this case.

The simplified analysis supported the analytical model. This conclusion demonstrated that direct measurement of the thermal conductivity of the installed foam was required to resolve the differences between calculated and measured temperatures.

The discovery of the void and modification of the model to account for it resulted in good agreement between the test and analytical results.

\section{Conclusions}

The thermal conductivity of the polyurethane foam as installed in the package was consistent with the manufacturer's data.

The simplified analysis was useful in confirming that the analytical results were valid, for the structure that was believed to exist.

The results simplified analysis was sufficiently accurate (within about 20\%) to correctly estimate the performance of package under NCT conditions.

\section{References}

1. Hardy, B., "NCT Thermal Model for the 9977 Package", SRNL Calculation M-CLC-A-00255, April 20, 2006, Appendix 3.3 of "Safety Analysis Report for Packaging, Model 9977, SSARP-G-00001, Vol. 2, Rev 1, April 2006.

2. Eberl, K. R., and Abramczyk, G. A., "9977 Thermal Benchmark Test", SRNL Report S-TSM-A-00001, March, 2006, Appendix 3.1 of "Safety Analysis Report for Packaging, Model 9977, S-SARP-G-00001, Vol. 2, Rev 1, April 2006.

3. Abremczyk, G. A. and Smith, A. C., "Test Summary Report of the 9977 Package SN-6 Structural and Thermal Property Evaluation", SRNL Report M-TSM-A-00007, Junary, 2007. 